Editorial Note

\title{
Folded Valuations?
}

\author{
Claes-Fredrik Helgesson
}

\section{Cringing valuation practices}

In a recently aired episode of the TV series Black Mirror we are invited into the world of Lacie. ${ }^{1}$ In the typical style of Black Mirror, we are invited into a social reality quite similar to our own, but with certain technologies somewhat enhanced. In the world of Lacie every social interaction, however insignificant, involves the activity of immediately rating one another on a scale from 1 to 5 . This significantly modifies most people's behaviour: they make great, and sometimes cringing, efforts to appear likeable so as to attract high ratings and improve their overall score. For instance, Lacie's brief encounter with Jack working at the coffee shop is performed with mutual smiles and pleasantries to then end with reciprocated ratings. We further soon learn that the overall score is far from a mere matter of vanity. Your score carries weight for job opportunities, in social life, and where you can live. ${ }^{2}$ In short, the score is highly consequential. No wonder that Lacie puts a lot of effort into improving her 4.2 score, including having sessions with a modern analyst/therapist about how to quickly bump up her numbers.

I would like to take the opportunity in this editorial note to reflect on the folding of different valuation practices. With the notion of folds and folding I want to denote both the instance where a valuation

\footnotetext{
1 'Nosedive', episode 1 season 3, first aired 21 October 2016.

2 The wide use of such a score has striking resonance with the 'citizen score card' developed in China as described by Julian Jürgenmeyer and Karoline Krenn in their contribution to this issue (Jürgenmeyer and Krenn 2016).

Claes-Fredrik Helgesson, Department of Thematic Studies-Technology and Social Change, Linköping University, claes-fredrik.helgesson@liu.se

(C) 2016 Authors

LiU Electronic Press, DOI 10.3384/VS. 2001-5992.164293

http://valuationstudies.liu.se
} 
practice is feeding and impinging on another valuation practice and the practices that achieve such interrelations between valuation practices. ${ }^{3}$ In the story about Lacie her worthiness as a co-worker or tenant was influenced by how she was rated even by the total strangers she briefly encountered. The particular folds between valuation practices in Lacie's world are naturally highly stylised to fit a 60minute storyline. In our own world they are far more varied, insidious, and (at least sometimes) sophisticated. How do different valuation practices influence and feed one another? With what means and efforts are such foldings brought about and with what consequences? What do we find if we look into the nooks and crannies of a conglomeration of interrelated valuation practices?

I would like to engage with these questions by profiting from my vantage point as co-Editor-in-Chief for a small academic journal. Just as David Pontille and Didier Torny (2014) recently talked about journal peer review as involving several different tests, I want to examine the multiple valuations related to scholarly journal publishing and in particular how they require us to think about how these valuation practices are folded into one another. We have in previous editorial notes written about valuations of scholarly publishing, but then typically focusing on one valuation practice in particular, such as the assessment of manuscripts as simultaneously work and valuation (Helgesson and Muniesa 2014), or reflecting on the precarious status of being a new and fledgling journal (Helgesson and Muniesa 2013). $\mathrm{My}$ attention in this editorial note is directed towards the folding of valuation practices into one another.

\section{An inventory of valuation practices}

Let's begin by making a provisional inventory of valuation practices directly or indirectly related to the making of a scholarly journal. One way to do this is to identify the valuation practices that centre on the various entities involved in scholarly journal publishing: manuscripts, authors, reviewers, editors, articles, readers, journals, publishers/ funders, etc.

Manuscripts are intimately tied in to the editorial process where one or several editors assess them and further involve reviewers in this extended task. While the manuscript is the main object of valuation in the editorial process, other entities such as reviewers, author(s), and editor(s) are also regularly subject to assessment in the editorial process. Who would be able and available to review this manuscript? What revisions might be within the capacity and interests of this

3 The way valuation practices may impinge on one another resonates with what Jürgenmeyer and Krenn in this issue call 'the feedback loops of valuation regimes' (Jürgenmeyer and Krenn 2016). 
particular author to achieve? Are the editors really giving my manuscript their full attention? Hence, the editorial process is in itself a highly extended and multifaceted valuation practice (see also Hirschauer 2010, 2014; Pontille and Torny 2014).

Another set of valuation practices centre around individual published articles. Published articles are assessed as they are read, discussed, criticised, praised, put on syllabus, and so on. In short, they become more or less valuable parts of the never-ending stream of conversations that makes up the core of the scholarly trade. One particular kind of valuation practice that tries to embrace and assess the social life and status of an article is the counting of citations. Instead of asking how to directly assess the worthiness of a given text, these practices home in on how many times a particular article has been cited by others. This has, in its turn, created many discussions about how to properly perform that counting and how well it represents other assessments of an article. Some journals furthermore participate in promulgating assessments of published articles. This can be done by providing lists of articles 'most cited' or 'most read'. (The latter is most often operationalised by using the proxy of downloads, which anyone who has a reading backlog would recognise as stretching what counts as reading.) In all, several valuation practices are tied to published articles, and some are far more metricised than others.

Journals are themselves the object of several valuations. Some take the indistinct form of gauging a journal's reputation among peers, normally glancing at particularly good (or bad) articles they have published and the esteem of published authors, editors, board members, and so on. Other valuations are more formalised, such as the one performed prior to including a journal in an index such as that maintained by the Directory of Open Access Journals (DOAJ). Similar processes are performed for entering more excluding lists and rankings such as the ABS list maintained by the Chartered Association of Business Schools, which ranks journals in disciplines related to business schools. ${ }^{4}$ There are furthermore metrics like rejection rate and impact factor, which measure impact as the average number of citations for articles published in that journal during the two preceding years. Journals are in addition assessed as part of their efforts to acquire necessary funding. Valuation Studies, for instance, is currently supported by the Swedish Research Council following review of an application. One would guess that commercial publishing houses do some kind of return-on-investment assessment of their many journals. I could go on. Even this tiny sample illustrates the variety of settings in which academic journals are assessed. This glance at journals as

${ }^{4}$ For a study of the creation of three other lists in the social sciences and humanities, see Pontille and Torny (2010). 
objects of valuation furthermore exemplifies a particular folding of assessments in that the assessment of a journal's impact factor is created by folding the assessment of articles in terms of citations.

Then we have the scholars. They appear in multiple roles in the area of scholarly journal publishing; they are authors, editors, reviewers, and readers. Scholars craft their curriculum vitae (CV), a written 'course of life', to display who they are, and other scholars use them as part of assessing applications for jobs, grants, and so on. A CV regularly documents several matters related to journal publishing such as articles published, reviewer assignments fulfilled, and possible editorial positions. Other assessments of scholars focus entirely on their capacities as authors and might in its crudest metric be expressed as a single integer of an h-index per examined author (the higher the hindex the better). Not only does the assessment of scholars partly rely on matters produced by journals, the converse is also true in that journals rely on the assessment of scholars for their operations. This includes editorial assessments of suitable reviewers and whether a particular proposer of a special issue proposal makes it worthy of a closer look. There is, however, a surprising lack of assessments of readers. I have yet to come across a CV listing 'Good articles read'. Even in the UK, where the academic title 'Reader' is used, it seems to be awarded based on the candidate's ability to publish rather than for being a particularly talented reader. Leaving this slight digression aside, there is, as most readers of this editorial are certainly aware, an impressive and sometimes even brutal set of ways in which scholars are assessed in relation to scholarly journal publishing. ${ }^{5}$

If all these different objects of valuation could only be voices in a massive choir sharing their experiences; the likely cacophony would be in many keys, but still worthy of attention. Listening carefully, we would discern a disrespected manuscript lamenting, in a minor key, how it got caught in a spiteful triumvirate of two contradictory reviewers and a directionless editor. Simultaneously we would hear another manuscript providing an uncontrollable chant of joy after having finally got out of a seemingly endless cycle of 'revise and resubmit'. A journal might howl about how impact factor measurements are completely ignoring whether it has a recognisable and worthy editorial scope or not, whereas another journal yodels about the merits of a particular rank where it happens to be in the top tier. Another possible set of voices would belong to reviewers who close to the deadline reprimand themselves for ever having accepted to review the manuscript they have only just now begun to read. A set of articles would contribute a complex cycle in many ways: some articles croon about their strange experience of increasingly being cited

5 Scholarly life, it seems to me, is an area begging to be examined in ways similar to the contribution by Henrik Fürst in this issue who has examined how aspiring fiction writers handle rejections (Fürst 2016). 
without being read while others chant about how it is to be read repeatedly without ever being cited. In the background there is a massive choir of articles humming about their ambiguous status of having been published only to be neither cited nor read. (We would need to listen carefully to hear them at all.) Bringing in the authors, editors, and readers for the chorus adds further to the cacophony, singing as they do to their hearts content about worthwhile reads, valuable contributions, h-indices, impact factors, and so on. It would be a massively loud, motley, and impressive choir.

What I have provided here is a very provisional inventory of valuation practices. Most academics could presumably add specific valuation practices I have failed to mention or indeed provide stories that would add more voices to the above imagined choir of experiences. My objective was not to be exhaustive, but to quickly establish that there is indeed a large and diverse set of valuation practices at play that are directly or indirectly related to the making of a scholarly journal. There are many objects assessed, many entities involved, and these valuation practices produce a rich variety of outcomes and experiences. Some are highly public, like citation counts, whereas others are carefully kept within narrow circles, such as the editorial decision letters and reviewer assessments. Moreover, these valuation practices are interrelated in complex ways. It is useful to think of these interrelations as 'foldings'.

\section{The folding of valuation practices}

I have already briefly indicated some foldings in the large conglomerate of valuation practices related to scholarly journal publishing. That these foldings exist is not surprising, since an interrelation between valuation practices is often part of their design. One example is how the counting of citations of a published article is folded into the impact assessment of the journal publishing the article as well as into assessments of its authors. Yet, there is reason to give the possible foldings of valuation practices more attention and to go beyond the most obvious interrelations. I will do this by first looking at two more subtle foldings, and then reflecting on the characterisation of different foldings and their consequences.

A few years ago the blog 'The Scholarly Kitchen' ran a blog post about the rapidly growing impact factor of the journal Cell Transplantation (Davis 2012). In 2006, this journal had had an impact factor of 3.482 and in 2010 it was 6.204, enough of an increase to be remarked upon. The post identified two other journals as especially prone to cite articles published in Cell Transplantation. In fact, two review articles in two other journals alone contributed 541 citations to articles published in Cell Transplantation in 2008 and 2009, and were hence included in the calculation of the 2010 impact factor for Cell 
Transplantation. Incidentally, the blog post added, a majority of the authors of these two review articles were members of the editorial board of Cell Transplantation. The blog post noted that this had continued. In addition, the journal Cell Transplantation had itself published a similar review article in 2010 that heavily cited articles in another journal. This article was co-authored by the editor-in-chief and a co-editor of the journal 'receiving' these citations. The blog post thus drew the contours of what it called a 'citation cartel', which is more difficult to detect than the practice of citing other articles in the same journal.

\footnotetext{
The ease to which members of an editorial board were able to use a cartel of journals to influence their journal's impact factor concerns me greatly because the cost to do so is very low, the rewards are astonishingly high, it is difficult to detect, and the practice can be facilitated very easily by overlapping editorial boards or through cooperative agreements between them. What's more, editors can protect these "reviews" from peer review if they are labeled as "editorial material," as some are. It's the perfect strategy for gaming the system. (Davis 2012)
}

Setting aside the judgemental notion of 'gaming the system', this is clearly another example of the complex foldings of valuation practices in scholarly journal publishing. Editors can in addition be authors and as such they might find it worthwhile to cite some articles published in the journal they are editing. Such activity not only adds lines to their individual CVs, but further increases citations to articles and may in this way add to the impact factor of the journal they edit. Finally, as the above quote indicates, it can be done in a way that circumvents the peer review process, for instance, by calling it editorial material (just as this editorial note).

The other folding I would like to mention concerns the practice of reviewing. In most circumstances it would be wrong to consider reviewers as decision makers over what gets published in a journal. That task is the chore of editors. Yet reviewers can of course through their reviews influence the judgements and decisions editors make. Imagine a situation where a reviewer reads a manuscript that is not terribly promising and, to add insult to injury, cites several of the reviewer's own works. Favourably, one should add. While this hardly compensates for the manuscript's shortcomings in the eye of the reviewer, it certainly may add a dimension to the practice of reviewing. What if the manuscript could be sufficiently improved to be acceptable for publication? In this age of personalised metrics, a reviewer might not only ponder how such a publication could reflect on his or her own scholarship, but in addition reflect on what it would mean for improving the reviewer's own h-index-another folding, possibly present at times, but not in a visible way. Let us call this an example of a 'torn reviewer situation'. 
The 'citation cartel' and the 'torn reviewer situation' are examples of subtle foldings between valuation practices in scholarly publishing. They highlight how different valuation practices exemplified in the inventory above may be folded into one another in less visible ways. The practice of reviewing might come to involve reflections about the reviewer's h-index, and an author's citing of an article might involve considerations about the impact factor of a journal. In a recent article in Nature Mario Biagioli (2016) mentions a few other similar instances of interrelated valuation practices, such as the 'review and citation ring' where favourable fake reviews are traded for citations of the reviewer's works. Biagioli further stresses that such 'cheats in the citation game' are enabled by the audit culture of universities, in love as they are with impact factors, citation statistics, and so on. One could restate this as a case where certain already highly folded valuation practices, such as those cherished by audit hungry universities, apparently stimulate further foldings of valuation practices.

It is striking how the examples of 'citation cartels', 'torn reviewer situations', and 'review and citation rings' share an element of being considered less legitimate. This would be indicated by how they attract labels such as gaming, cheating, and self-seeking. The ease with which we recognise certain foldings as legitimate, and others as less legitimate, is an important topic in its own right. An author publishing an article would rarely be considered as 'gaming the system', even though it clearly adds a new line to the author's CV. Repeated selfcitation, would, on the other hand, easily attract such a derogatory labelling. ${ }^{6}$ Hence, there is an interesting dynamic here as to characterising the folding of valuation practices as proper or improper, legitimate or illegitimate. Instead of taking such characterisations as representing intrinsic qualities of specific foldings, an analytic approach here would be to consider the declaration of such characterisations as part of the politics of the folding of valuation practices. The presence of such a categorical characterisation is, in my view, a clear indication of the importance of a detailed examination of how valuation practices are folded into one another. In a detailed examination of foldings, it would only be prudent to include an investigation of how certain foldings come to be considered as proper while others come to be considered as improper.

There are perhaps further analytical possibilities to be had from taking seriously all the diverse foldings of valuation practices related to scholarly journal publishing. It might, for instance, provide a vantage point for examining research excellence as a practical achievement. It might, furthermore, provide a way to examine how the Matthew

${ }^{6}$ Guilty as charged? I do understand that the self-citations in this editorial note may attract such harsh judgements. 
effects in science (Merton 1968) are brought about without evoking psychosocial mechanisms. ${ }^{7}$ Among other things, Merton pointed to how publications by known scholars might be more recognised. As an indicator he suggested a look at "citation indexes to find whether in multiple discoveries by scientists of markedly unequal rank it is indeed the case that work published by the scientists of higher rank is the more promptly and more widely cited." (Merton 1968: 60) Attention to the folding of valuation practices would suggest examining citation indexes as part of the folded valuation practices that can produce Matthew effects, rather than seeing them as only providing possible indicators of such effects.

One prominent theme in the study of valuation practices in various settings has been to examine how their configuration participates in shaping the enactment and negotiation of different values. The many valuation practices involved in scholarly publishing provide fertile grounds for examining this, be it the editorial process or the calculation of h-index. What I have briefly explored here is the folding of several valuation practices in scholarly journal publishing. Just as each valuation practice is wrought with the enactment and negotiation of different values, so are the foldings. Hence, the study of valuations as a social practice can fruitfully address the enactment and negotiation of values that come from the very folding of valuation practices on to one another.

\section{The black mirror of folded valuation practices}

This editorial note has provided a brief reflection on what you see when you look into a black mirror of folded valuation practices. The reflection might not only be dark, although dark hues are certainly present. With the notion of folds and folding I wanted to address instances where one valuation practice is feeding and impinging on another valuation practice and the activities that achieve such interrelations between valuation practices. Addressing the folding of valuation practices invites looking at a complexity of interrelations and activities that escapes our view when we focus on a singular valuation practice. ${ }^{8}$ Looking into the nooks and crannies of a conglomeration of interrelated valuation practices further provides a

7 The Matthew effect in science is to denote that already better recognised researchers are more likely to gain further recognition than are less well-known researchers, even if the latters' work is similar. Merton evoked psychosocial mechanisms for explaining this, such as that successful scientists tried harder since more became expected of them.

${ }^{8} \mathrm{~A}$ related theme is how new valuations practices or devices need to relate to folded valuations already in place, as described by Amalie Martinus Hauge (2016) in this issue. Moreover, the contribution in this issue by Erwin Dekker on exemplars further reminds us that judgement devices indeed in themselves can be multidimensional and folded (Dekker 2016). 
glimpse of a politics beyond the singular valuation practice; this is the politics of how valuation practices are folded on to one another, and how these folds are characterised.

The folding of valuations can, it seems, be a politics of high stakes. This is furthermore at the same time as the folding of valuations can lack an identifiable centre or well-defined locus of accountability. When looking into the black mirror of folded valuation practices we see no singular valuation practice, no singular individual, responsible for sealing the fate of Lacie. The fate of Lacie was all achieved by folds.

Acknowledgements. My reflections on the folding of valuation practices in scholarly journal publishing originate from a talk titled 'The valuation practices of academic publishing: Remarks from the outlook of the new journal Valuation Studies' that I gave at the workshop 'Intellectual Property and the Politics of Knowledge' at the Institute of Advanced Legal Studies in London, 20 May 2016. The workshop was convened by Hyo Yoon Kang and Jose Bellido, both at University of Kent, whose encouragement for developing my talk is greatly appreciated. This note has benefited from comments and encouragement provided by David Moats and Steve Woolgar as well as my colleagues on the board of editors of Valuation Studies: Liliana Doganova, Martin Giraudeau, Hans Kjellberg, Francis Lee, Alexandre Mallard, Andrea Mennicken, Fabian Muniesa, Ebba Sjögren, and Teun Zuiderent-Jerak.

\section{References}

Biagioli, Mario. 2016. "Watch out for Cheats in the Citation Game." Nature 535(7611): 201.

Davis, Phil. 2012. "The Emergence of a Citation Cartel." https:// scholarlykitchen.sspnet.org/2012/04/10/emergence-of-a-citation-cartel/, accessed 28 November 2016.

Dekker, Erwin. 2016. "Exemplary Goods: Exemplars as Judgment Devices." Valuation Studies 4(2): 103-124.

Fürst, Henrik. 2016. "Handling Rejection as Failure: Aspiring Writers Getting the Rejection Slip.” Valuation Studies 4(2): 153-176.

Helgesson, Claes-Fredrik, and Fabian Muniesa. 2013. "For What It's Worth: An Introduction to Valuation Studies." Valuation Studies 1(1): 1-10.

—. 2014. "Valuation Is Work." Valuation Studies 2(1): 1-4.

Hirschauer, Stefan. 2010. "Editorial Judgments: A Praxeology of 'Voting' in Peer Review.” Social Studies of Science 40(1): 71-103. 


\section{Valuation Studies}

. 2014. "How Editors Decide. Oral Communication in Journal Peer Review." Human Studies 38(1): 37-55.

Jürgenmeyer, Julian, and Karoline Krenn. 2016. "Classification Situations: A New Field of Research for Valuation Studies?” Valuation Studies 4(2): 177-189.

Martinus Hauge, Amalie. 2016. "The Organizational Valuation of Valuation Devices: Putting Lean Whiteboard Management to Work in a Hospital Department." Valuation Studies 4(2): 125-151.

Merton, Robert K. 1968. "The Matthew Effect in Science." Science 159(3810): 56-63.

Pontille, David, and Didier Torny. 2010. "The Controversial Policies of Journal Ratings: Evaluating Social Sciences and Humanities." Research Evaluation 19(5): 347-360.

- 2014. "From Manuscript Evaluation to Article Valuation: The Changing Technologies of Journal Peer Review." Human Studies 38(1): 57-79.

Claes-Fredrik Helgesson is co-Editor-in-Chief of Valuation Studies and Professor in Technology and Social Change at Linköping University, Sweden. He is co-Editor with Isabelle Dussauge and Francis Lee of the volume Value Practices in the Life Sciences and Medicine (Oxford University Press, 2015). Helgesson is currently concluding with Francis Lee the research project 'Trials of Value' which explores valuation practices in the context of experimental design in biomedical research. 